\title{
The Long March for Science in Defense of Population Health
}

Rare grand initiatives and discoveries aside, population health and its supporting science usually advance by the slow accretion and sharing of a myriad of capacities, findings and interventions across the global scientific community. In the best of cases, ordinary people benefit. But in the worst cases, science is shunted aside, ignored or twisted to fit interests that actively oppose the right to health.

Among those threatened today are indigenous health, reproductive rights, quality health care for marginalized populations and entire continents, planetary health, and certainly health in all policies. A version of "racial and economic profiling" turns patients into clients or turns them away altogether. These are some reasons why health professionals and researchers have taken to the streets with entire communities, defending their work to improve medicine and health equity: "I can't believe we have to march for science...yet we do," one prestigious scholar put it.

The first step along this march is often getting the word out. This is the case of the chronic kidney disease (CKD) epidemic in Central America and elsewhere, until recently a silent killer of over 20,000 subsistence farmers and their families in El Salvador alone. MEDICC Review is proud to be among the journals that first called attention to this disease of nontraditional causes that fells people often too poor and too sick to join any march. In this issue we carry research that raises important hypotheses on the causes of the epidemic, as Orantes' paper analyzes findings from a national Salvadoran survey, implicating both working conditions and agrochemical exposure in this CKD etiology.

Yet, when it comes to getting the word out, population health researchers from the Global South are often at a distinct disadvantage, especially publishing in international peer-reviewed journals, ever more so if their native language isn't English. They are also hampered by the dearth of scientific writing courses in their medical and health sciences curricula. Thus, their research may be flawless, but their work is like the proverbial light hidden under a bushel basket. And the whole world suffers as a result, particularly those who most need their research.

MEDICC Review is pleased in this regard to collaborate with Cuba's National School of Public Health and PAHO/WHO in an annual Scientific Writing Course offered in Havana. The course's fourth edition this year enrolled another 50 participants, manuscripts in hand, who attended interactive lectures, workshops and tutorial sessions. We... and indeed other journals...look forward to receiving their papers.

While we are dedicated primarily to publishing work from Cuban professionals in health and related fields, MEDICC Review is committed to raising the profile of research and opinion from the Global South as a whole. In this issue, we're glad to see a variety of countries represented among our authors, including Chile, Colombia, El Salvador, Panama, and the Dominican Republic-as well as Cuba, the USA and UK.

All have one thing in common: their goal is to apply their discoveries, intelligence and commitment to produce scientific evidence that addresses big population health issues, and uses modern as well as traditional tools to do so. Thus, our pages reflect progress in genetic, statistical and biological analyses, allowing for greater precision in diagnosis and treatment plans, earlier disease detection, or more accurate prediction of disease appearance and progression. Gari-Llanes' study of pediatric hypertension examines its relationship to the biochemical risk markers most associated with cardiovascular disease in adults. The importance of her research can't be over-emphasized, since cardiovascular disease is expected to take a much greater toll in middle- and low-income countries over the next decades.

\section{MEDICC Review is \\ committed to raising \\ the profile of research \\ and opinion from the \\ Global South}

Using a novel statistical approach to dengue data, LópezMontenegro of Colombia develops a model to forecast dengue outbreaks, allowing for more precise and effective control strategies. In the sphere of pharmacology, Garcia-Blanco of Cuba looks at antiretroviral therapy for HIV through the prism of genetics, reviewing the latest literature from around the world to discover reasons for adverse drug reactions.

Other contributions turn their sights on the implications of population aging, a fact of life and longevity in Latin America and many other regions. Hirmas-Adauy assesses the effectiveness of a public policy in Chile designed to provide assistive devices to older adults, and Villareal provides the first study of cognitive impairment in Panama's aging population, serving as a baseline for further research on early detection. Women of science are represented in a preponderance of authorship in this issue, and in the intersection of race and gender explored in Gorry's interview of Cuban anthropologist Lourdes Serrano.

Recent news of measles outbreaks and emergencies across the USA, as well as Ebola's leap across the border from Congo to Uganda, are potent reminders that progress towards universal and planetary health need both science in the public interest and a public interested in science. Not only interested, but also placing their trust in fruits of rigorous science. This is why MEDICC Review and other peer-reviewed journals publish, but also why we encourage scientists to go beyond our pages to make the argument to a wider audience. This wider audience, after all, will cast the deciding vote on whether health, their own and others', is worth marching for. - w -

\section{The Editors}

